\title{
Transcriptome profiling of genes and pathways associated with arsenic toxicity and tolerance in Arabidopsis
}

\author{
Shih-Feng Fu ${ }^{1 \dagger}$, Po-Yu Chen ${ }^{2 \dagger}$, Quynh Thi Thuy Nguyen ${ }^{2+}$, Li-Yao Huang ${ }^{2}$, Guan-Ru Zeng ${ }^{2}$, Tsai-Lien Huang ${ }^{2}$,
} Chung-Yi Lin ${ }^{2}$ and Hao-Jen Huang ${ }^{2^{*}}$

\begin{abstract}
Background: Arsenic (As) is a toxic metalloid found ubiquitously in the environment and widely considered an acute poison and carcinogen. However, the molecular mechanisms of the plant response to As and ensuing tolerance have not been extensively characterized. Here, we report on transcriptional changes with As treatment in two Arabidopsis accessions, Col-0 and Ws-2.

Results: The root elongation rate was greater for Col-0 than Ws-2 with As exposure. Accumulation of As was lower in the more tolerant accession Col-0 than in Ws-2. We compared the effect of As exposure on genome-wide gene expression in the two accessions by comparative microarray assay. The genes related to heat response and oxidative stresses were common to both accessions, which indicates conserved As stress-associated responses for the two accessions. Most of the specific response genes encoded heat shock proteins, heat shock factors, ubiquitin and aquaporin transporters. Genes coding for ethylene-signalling components were enriched in As-tolerant Col-0 with As exposure. A tolerance-associated gene candidate encoding Leucine-Rich Repeat receptor-like kinase VIII (LRR-RLK VIII) was selected for functional characterization. Genetic loss-of-function analysis of the LRR-RLK VIII gene revealed altered As sensitivity and the metal accumulation in roots.

Conclusions: Thus, ethylene-related pathways, maintenance of protein structure and LRR-RLK VIII-mediated signalling may be important mechanisms for toxicity and tolerance to As in the species. Here, we provide a comprehensive survey of global transcriptional regulation for As and identify stress- and tolerance-associated genes responding to As.
\end{abstract}

Keywords: Arsenate, Arabidopsis accession, Microarray

\section{Background}

Arsenic (As) is a ubiquitously present non-essential metalloid of serious environmental concern because of everincreasing contamination $[1,2]$. Naturally high levels of As in drinking water have caused major human health problems in the United States, Argentina, Taiwan, and most notably Bangladesh and India, where tens of millions of people have been affected [3,4]. As finds its way into the food chain through irrigation with contaminated groundwater [5]. Uptake of As in plant tissues adversely affects

\footnotetext{
* Correspondence: haojen@mail.ncku.edu.tw

'Equal contributors

2Department of Life Sciences, National Cheng Kung University, No.1

University Road 701, Tainan, Taiwan

Full list of author information is available at the end of the article
}

the plant metabolism and leads to a significant reduction in crop yield [6-8]. Understanding of As-induced stress and ensuing tolerance would be beneficial for the development of As-resistance crops and other economically important plants [8].

Roots are involved in mineral acquisition by plants, and function at the interface with the rhizosphere. Alterations of root architecture and inhibition of root elongation are considered primary symptoms of As-toxicity $[9,10]$. In many circumstances, it is the As-sensitivity of the root that limits the productivity of the entire plant [11]. Hence, plants exposed to As show inhibited root growth and reduced photosynthetic rate $[8,12]$. While plant roots are the first organs in contact with As, assaying the processes

\section{(Ciomed Central}


occurring in the roots could provide potential strategies to determine how plants respond and adapt to the heavy metal stress.

As is present both as As (III) and As (V) in the environment, with As (V) being more prevalent than As (III) in soils $[8,13]$. The mechanism by which As is taken up by plants differs for As(III) and As(V) [14]. As (III) uptake is thought to occur through the aquaporins of roots [14,15]. Higher plants take up As (V) as the dominant form of phytoavailable As in aerobic soils. As (V) is a phosphate analogue and easily incorporated into plant cells through the high-affinity phosphate transport system $[8,14]$. As (V) replaces phosphate in ATP to form unstable "ADP-As" complexes and disrupts energy flow in cells [8]. As (III) reacts with the sulfhydryl groups of enzymes and proteins, thereby inhibiting cellular function and resulting in cell death $[8,16]$. In addition, As stimulates the formation of free radicals and reactive oxygen species, thus resulting in oxidative stress $[9,10,17]$.

Detoxification and tolerance mechanisms often involve extrusion of the toxic ions from cells, sequestration within internal organelles, reduced toxin uptake, and chelation by metal-binding proteins such as phytochelatins (PCs) [18]. These mechanisms reduce the cellular content of the toxic agent, although the molecular basis may differ among metals and organisms [19-21]. Differences in As sensitivities exist among plant accessions or varieties [11,22,23]. Understanding the mechanisms underlying reduced As sensitivity and genes responsible is important in directing future breeding to counter As stress. The potential of As tolerance, based on such a concerted response of the various pathways, would also depend on an early perception of As-induced stress [10]. The precise mechanisms of perception of As-induced stress in plants remain to be elucidated.

Reducing As intake requires identifying the mechanisms implicated in As toxicity and tolerance in plants. A substantial number of genes are differentially regulated by As stress in various plant species $[9,10,24]$. However, genes identified as As responsive are in part related to a general stress response resulting from the toxic effects of As and are unlikely to play a significant role in As tolerance. High-throughput gene expression profiles with microarray technology and their application in comparative studies help to reveal the roles of differential gene regulation in As toxicity and tolerance. For more insight into the molecular basis of As toxicity and tolerance responses in plants, we performed transcriptional profiling of 2 contrasting accessions of Arabidopsis thaliana, Col-0 and Ws-2. We focused on genes that are commonly and specifically regulated by the two accessions and discuss the putative functions of identified genes in several biochemical pathways in terms of As toxicity and tolerance. New genes identified may provide more clues to understanding the molecular mechanism of response to As-induced stress in plants.

\section{Results}

\section{Effects of As stress on root elongation in Arabidopsis} accessions Col-0 and Ws-2

Root growth inhibition is the primary response of the plant exposed to heavy metals. We analyzed the effect of As (V) exposure on primary root elongation to evaluate As toxicity and tolerance in $A$. thaliana accessions, including Col-0, Ws-2 and Ler-0. As a result, we examined accessions for As tolerance and exposed 1 tolerant (Col- 0 ) and 1 sensitive (Ws-2) accession to As for $2 \mathrm{~d}$ for measuring root elongation (Figure 1a). At $100 \mu \mathrm{M}$, As significantly reduced root elongation in both Arabidopsis accessions as compared with normal conditions (Figure 1a). Of note, Col-0 showed less reduction in root elongation (15\%) than Ws-2 (50\%). The root elongation decreased with increasing As concentration (Figure 1b). At $200 \mu \mathrm{M}$ As, the reduction in root elongation in Col-0 was $40 \%$ as compared with $60 \%$ in Ws-2. At $300 \mu \mathrm{M}$ As, root growth was minimal in Col-0 and completely inhibited in Ws-2. As at 200 and $100 \mu \mathrm{M}$ inhibited root elongation by approximately one-half in Col-0 and Ws-2, respectively. Col-0 was more tolerant to As than Ws-2. Therefore, we hereafter refer to Col- 0 as As tolerant and Ws- 2 as As sensitive.

\section{Accumulation of As concentration in Arabidopsis roots with As exposure}

To investigate whether the differences in As tolerance in the two accessions was associated with As concentration in roots, we exposed root tips to As concentrations for $3 \mathrm{~h}$ and $48 \mathrm{~h}$ (Figure 1c). When exposed to As for $3 \mathrm{~h}$, As was increased in roots of both accessions with increasing As concentration. The concentration of As was lower in the As-tolerant than As-sensitive accession (Figure 1c). Note that at $48 \mathrm{~h}$, concentration of As was accumulated to a similar level in As-sensitive and As-tolerant accession, which possibly resulted from a more severely inhibited transpiration rate. Taken together, As accumulation in the roots of both accessions was associated with As concentration, with greater accumulation in Ws-2 than Col-0. The data may explain the differences in As toxicity and tolerance between the two accessions.

\section{Global expression profiles of Col-0 and Ws-2 in response to As}

To identify genes associated with As toxicity and tolerance in Arabidopsis, we used large-scale expression profiling. The As exposure data (Figure 1) helped determine a suitable As concentration for microarray analysis. Treatment of Col-0 and Ws-2 with As at 200 and $100 \mu \mathrm{M}$, respectively, had similar effects on root growth inhibition, indicating equal toxic strength. RNA samples were collected 

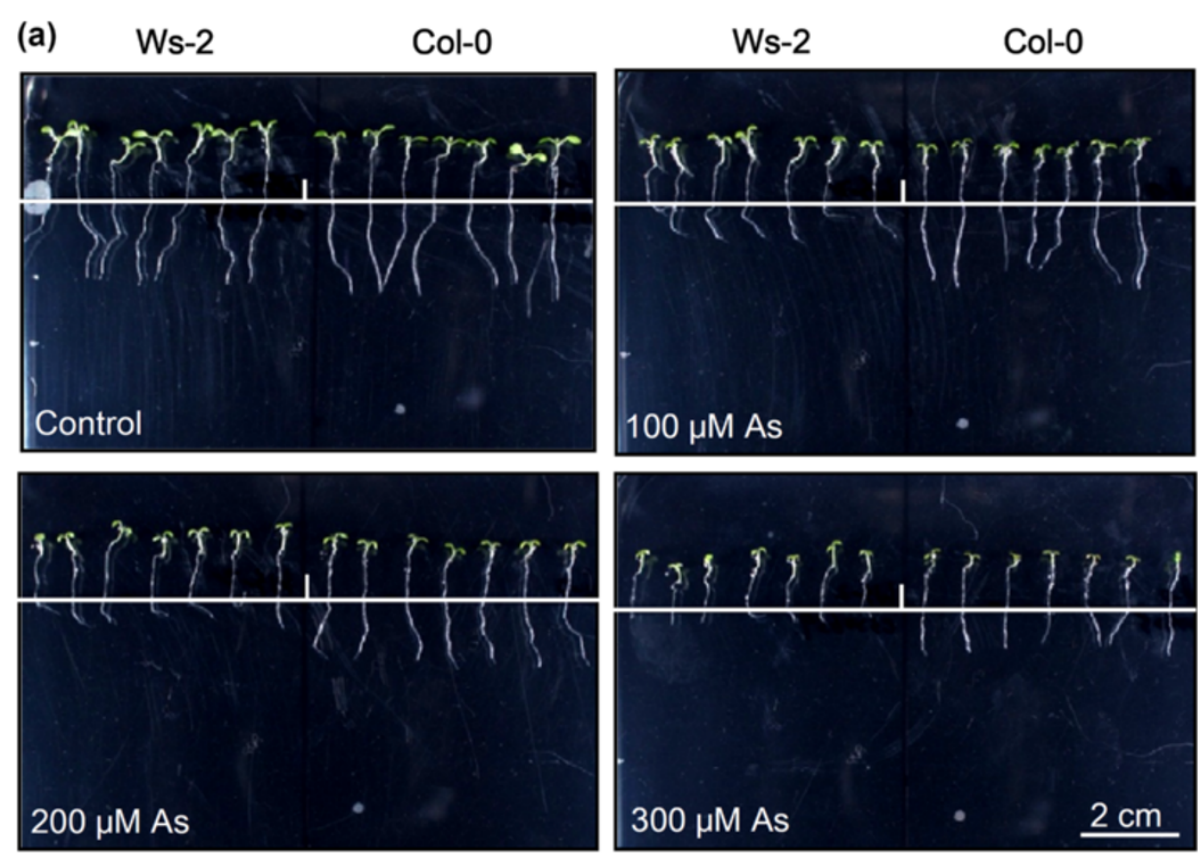

(b)

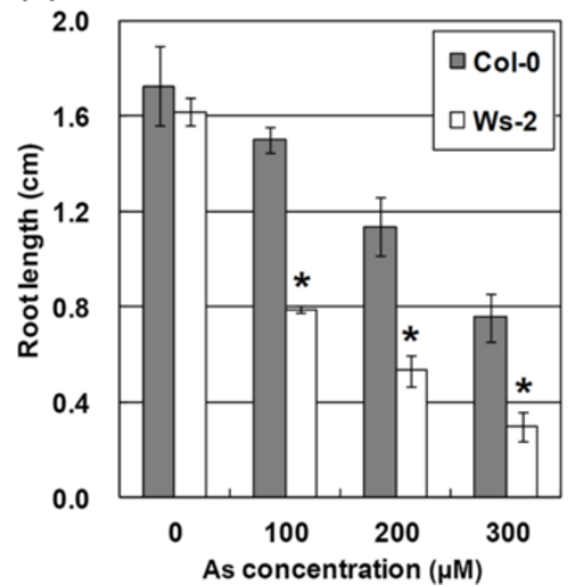

(c)

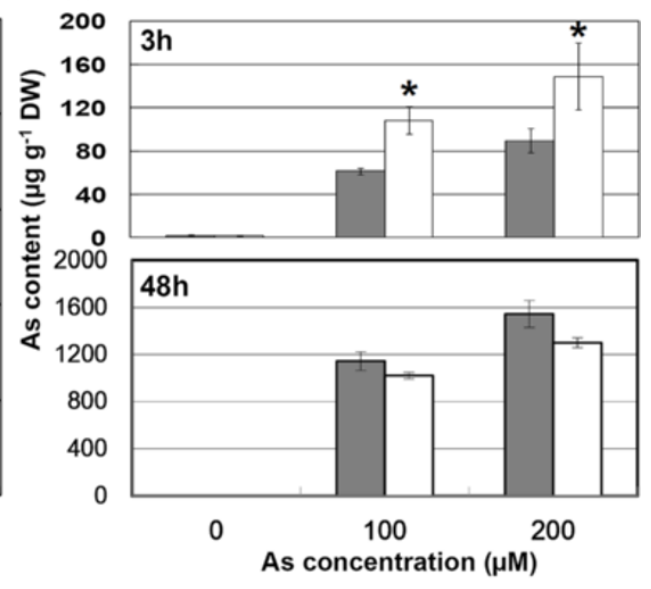

Figure 1 Effect of As (V) treatment on the root elongation and metal accumulation of Arabidopsis thaliana accessions Col-0 and Ws-2. (a) Seedlings with different accession backgrounds (Col-0 and Ws-2) were grown on quarter-strength MS medium for $4 \mathrm{~d}$ and then transferred to medium with 100, 200 and $300 \mu \mathrm{M}$ As (V) and grown for an additional $2 \mathrm{~d}$ (Scale bar, $2 \mathrm{~cm}$ ). As tolerance was determined by relative root growth after treatment. (b) Root length of plants was measured after treatment with As. Root samples were collected from 3 independent experiments (each from a pool of 7 root samples). Data are mean \pm SD. ${ }^{*} P \leq 0.05$ compared with Col-0 in each concentration of As. The difference in root elongation is significant according to Student's t test. (c) Accumulation of As ( $V$ ) by Arabidopsis accessions Col-0 and Ws-2 was analyzed with ICP-AES. The 4-d-old seedlings with different accession backgrounds (Col-0 and Ws-2) were transferred to medium containing 100 and $200 \mu \mathrm{M}$ As ( $V$ ) for $3 \mathrm{~h}$ and $48 \mathrm{~h}$, then root tips were collected and measured. Data are mean \pm SD calculated from 3 biological replicates per treatment. *P $\leq 0.05$ compared with Col-0.

from root tips early (1.5 to $3 \mathrm{~h})$ after As treatment to examine rapid changes in global patterns of gene expression. We pooled RNA isolated from with 1.5- and 3-h As treatment to maximize gene discovery.

Fold-change values were compared with a control sample without As treatment. Differentially expressed genes were defined as those with at least 2-fold change in transcript abundance and with an adjusted $\mathrm{P}$ value less than
0.05 [25]. In general, the As-tolerant and As-sensitive accessions showed similar expression patterns in the control conditions. Therefore, constitutive gene expression was similar between the two accessions before As treatment. In total, 620 probe sets were specifically upregulated in As-tolerant Col-0 plants exposed to $200 \mu \mathrm{M}$ As (Col-0 $200 \mu \mathrm{M}$ As versus Col-0 control) and 756 were downregulated (Figure 2a). These 1376 As-regulated genes were 

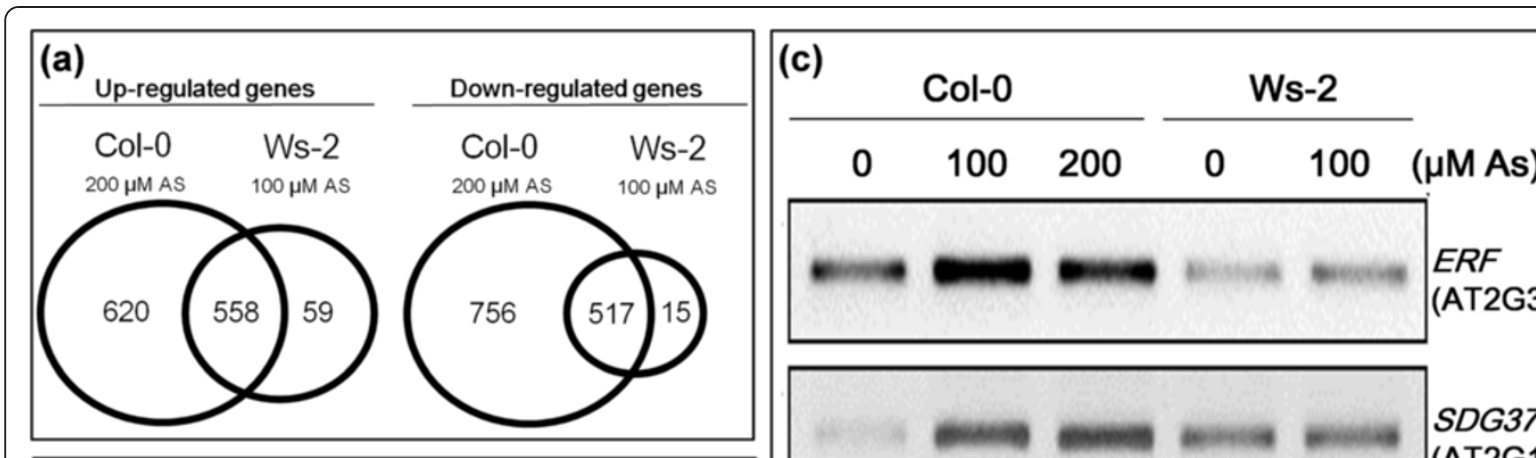

(AT2G33710)
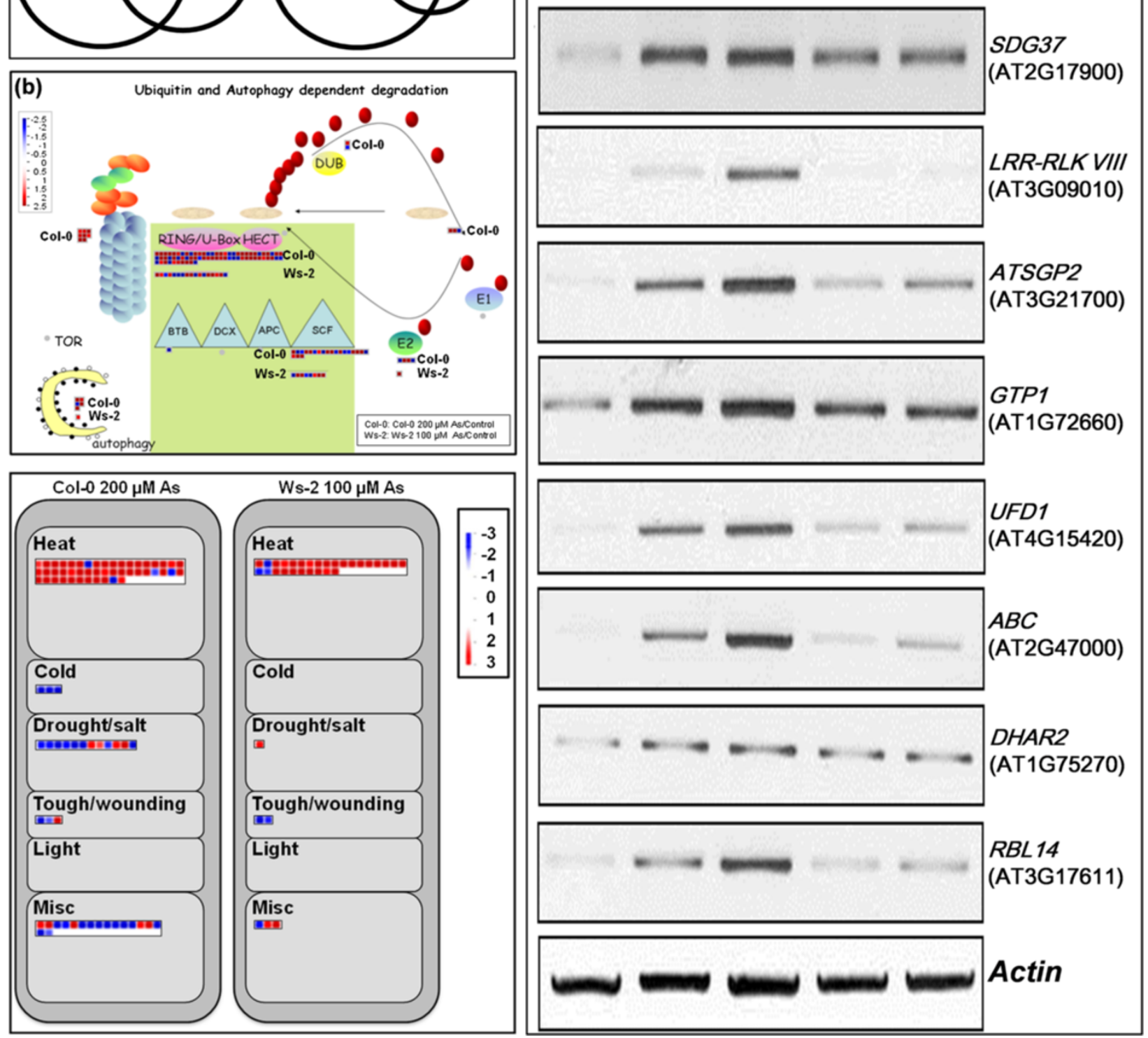

Figure $\mathbf{2}$ (See legend on next page.) 
(See figure on previous page.)

Figure 2 Microarray expression of genes in Arabidopsis Col-0 and Ws-2 plants exposed to As stress. (a) Venn diagram of regulated As-responsive genes extracted by comparing microarray probe sets of the 2 Arabidopsis accessions. The number of overlapping and non-overlapping genes early (1.5 to $3 \mathrm{~h}$ ) after treatment with 100 or $200 \mu \mathrm{M}$ As is shown. The probe sets were selected on the basis of an adjusted P-value of $<0.05$ and a $>2$-fold change in gene expression. The area of the diagram is proportional to the number of genes that are up- or downregulated in response to As stress. To clearly differentiate As-regulated genes in Col-0 from that in Ws-2, the Col-0-specific set contains only those genes with both $>2$-fold change in abundance (compared with control treatment) in Col-0 and <1.4-fold change in Ws-2. Likewise, the Ws-2-specific set contains genes with both > 2fold change in abundance in Ws-2 and $<1.4$-fold change in Col-0. The general As-regulated gene set contains genes displaying $>2$-fold change in abundance in Col-0 or Ws-2 and >1.4-fold change in another accession. (b) Displayed are genes associated with ubiquitin pathways and abiotic stress responses using MapMan software. Both sets of material were harvested from roots tissues treated with or without As stress (100 and $200 \mu \mathrm{M}$ for Ws-2 and Col-0, respectively). Red and blue signals represent a decrease and increase in transcript abundance, respectively, relative to water-treated control samples. The scale used for coloration of signals ( $\log _{2}$ ratios) is presented. (c) Validation of representative As-induced genes by semi-quantitative RT-PCR analysis. Total RNA was extracted from root tissues of Arabidopsis plants with different accessions with As treatment. The As-treated roots were harvested at 1 and $3 \mathrm{~h}$. The samples were pooled together. The transcript level of actin served as an equal loading control.

unique to Col-0. In Ws-2, 59 probes were upregulated in response to $100 \mu \mathrm{M}$ As (Ws-2 $100 \mu \mathrm{M}$ As versus Ws-2 control) and 15 were downregulated. These 74 Asregulated genes were unique to Ws-2. A total of 558 probes were significantly upregulated in both Col-0 and Ws-2 and 517 were downregulated in both (Additional file 1: Table S1 for full list). Thus, a relatively larger number of genes showed changed expression with As in Col-0, which suggests differential cellular response with early As exposure.

\section{GO analysis of As-responsive genes}

We subjected genes up- and downregulated with As stress to $\mathrm{GO}$ analysis using the EasyGO program to understand the metabolic and regulatory differences between the two accessions on As exposure. The major GO terms for biological processes for As-responsive genes are summarized (Table 1). Upregulated genes for both accessions were in functional categories corresponding to responses to heat, oxidative stress, and metal ion and carbohydrate stimulus. Col-0-specific genes were involved in responses to ethylene

Table 1 Gene ontology categories corresponding to genes differentially regulated by As in Arabidopsis accessions exposed to As

\begin{tabular}{|c|c|c|c|c|}
\hline Biological process & Accession $^{a}$ & No. genes ${ }^{a}$ & Background & False discovery rates \\
\hline \multicolumn{5}{|c|}{ Upregulated generally by As (V) } \\
\hline Heat response & Col-0, Ws-2 & 49,32 & 114 & $1.70 \mathrm{E}-27,1.95 \mathrm{E}-25$ \\
\hline Oxidative stress & Col-0, Ws-2 & 42,29 & 258 & 1.06E-9, 2.87E-13 \\
\hline Chitin response & Col-0, Ws-2 & 41,11 & 127 & 7.05E-19, 1,39E-5 \\
\hline Metal ion response & Col-0, Ws-2 & 44,17 & 367 & $2.58 \mathrm{E}-06,0.00799$ \\
\hline Carbohydrate stimulus & Col-0, Ws-2 & 50,14 & 203 & $5.80 E-21,0.000626$ \\
\hline \multicolumn{5}{|c|}{ Upregulated specifically by As (V) } \\
\hline Ethylene response & Col-0 (Ws-2) & $16,(5)$ & 143 & $5.01 \mathrm{E}-05$ \\
\hline ABA response & Col-0 (Ws-2) & $14,(6)$ & 262 & 0.00773 \\
\hline Heat acclimation & Col-0 (Ws-2) & $5(2)$ & 15 & 0.00154 \\
\hline Osmotic stress & Ws-2 (Col-0) & $16(7)$ & 391 & 0.0346 \\
\hline Toxin response & Ws-2 (Col-0) & $16(10)$ & 66 & $5.54 \mathrm{E}-12$ \\
\hline \multicolumn{5}{|c|}{ Downregulated generally by As (V) } \\
\hline Cell wall organization & Col-0, Ws-2 & 49,12 & 263 & $3.01 \mathrm{E}-12,3.81 \mathrm{E}-05$ \\
\hline Secondary metabolic process & Col-0, Ws-2 & 47,18 & 359 & $2.50 \mathrm{E}-07,9.42 \mathrm{E}-06$ \\
\hline Cytokinin response & Col-0, Ws-2 & 8,6 & 75 & $0.0196,0.0066$ \\
\hline Glycoside biosynthesis & Col-0, Ws-2 & 12,11 & 32 & 8.31E-06, 4.30E-11 \\
\hline Transport & Col-0, Ws-2 & 73,33 & 1732 & $0.0499,0.0289$ \\
\hline \multicolumn{5}{|c|}{ Downregulated specifically by As (V) } \\
\hline Receptor protein signaling & Col-0 & 30 & 130 & 1,96E-09 \\
\hline
\end{tabular}

${ }^{a}$ Accession specificity were identified according to false discovery rates $(F D R<0.05)$ of gene ontology analysis. Accession and no. of genes in parentheses refers to FDR $>0.05$ in each gene ontology term. 
stimulus and abscisic acid (ABA) and heat acclimation. Ws-2-specific genes were involved in osmotic stress and toxin response. Downregulated genes in both accessions were predominately involved in cell wall organization, response to cytokinin, glycoside biosynthesis and transport (Table 1). Col-0-specific downregulated genes were related to receptor protein signaling pathway with As stress.

To expand the functional significance of the Asresponsive genes in Col-0 and Ws-2, we used MapMan representations to highlight microarray data and biochemical pathways. Col-0-specific genes with changed expression were involved in the proteasome and heat stress (Figure 2b). The sulfur assimilation pathway, which leads to phytochelatin biosynthesis, is affected by As stress in both accessions (Additional file 2: Figure S1). The gene encoding phytochelatin synthase was upregulated only in Col-0 plants after exposure to As stress.

\section{Oxidative stress-related genes regulated by As exposure}

The As-responsive genes can be grouped into various biological processes such as oxidative stress, transporter, hormone homeostasis and signal transduction. First, the expression levels of the genes dealing with the responses to oxidative stress were compared between the two accessions (Additional file 1: Tables S2 and S3). Expression of genes coding for alternative oxidase, dehydroascorbate reductase, glutaredoxin, peroxidase were regulated in both accessions on exposure to As stress (Additional file 1: Table S2). In addition, a number of genes encoding thioredoxin were mostly induced in tolerant Col-0. Genes encoding glutathione S-transferases (GSTs) were predominately upregulated by As in both accessions. A total of 14 genes encoding for GST were upregulated in As-sensitive Ws-2, and 9 GST genes were induced in As-tolerant Col-0. Most of the As-responsive GST genes belong to the 40-member Tau class GSTs [26]. Fewer GST-related genes were upregulated in As-tolerant Col-0 than in As-sensitive Ws-2.

\section{Transporter genes regulated by As exposure}

A significant number of genes encoding transporters were differentially expressed in the As-sensitive and As-tolerant accessions with As exposure (Additional file 1: Table S4). ATP-binding cassette $(\mathrm{ABC})$ transporters comprised the largest group of transporter-related genes (Additional file 1: Table S2). A total of 9 and $14 \mathrm{ABC}$ transporter genes were differentially regulated in the Ws- 2 and Col- 0 accessions, respectively. Transcripts for genes from the multidrug and toxic compound extrusion (MATE) transporters and antiporters were also regulated by As treatment. Genes annotated as aquaporin, LeOPT1 oligopeptide transporters (OPT) and sugar transporter were predominately downregulated in Col-0 with As exposure, which suggests the differential regulation of transporter-related genes between the two accessions in response to As stress.

\section{Hormonal genes regulated by As exposure}

To understand the expression pattern of genes involved in hormone pathways between the As-sensitive and As-tolerant accessions, we analyzed transcripts related to hormone metabolism and found a potential role of ABA, brassinosteroid, cytokinin and ethylene in an early response to As stress (Additional file 1: Table S5). Genes encoding proteins involved in cytokinin homeostasis were mostly downregulated by As stress in both accessions (Additional file 1: Table S2). ABA-related genes were regulated (expression level $2 \sim 5$ fold change) predominately in As-tolerant Col-0. In total, 14 and 5 ethylene-related genes (expression level $2 \sim 26$ fold change) were regulated in the Col-0 and Ws-2 accessions, respectively. Ethylene biosynthesis- and signaling-related genes were regulated by As stress, especially in As-tolerant Col-0.

\section{Transcription factors and protein kinases regulated by As exposure}

In total, 200 and 69 genes encoding transcription factors were differentially expressed with As exposure in As-tolerant Col-0 and As-sensitive Ws-2, respectively (Additional file 1: Table S6). Col-0 showed more genes induced: APETALA2/ethylene-responsive-element-binding protein (AP2/EREBP), Aux/IAA, heat shock transcription factor (HSF), and WRKY (Additional file 1: Table S2). Genes encoding bHLH, C2H2, GARP-G2-like, and MYB were predominately downregulated in Col-0. Further, members of the AP2/EREBP, HSF and WRKY families were upregulated specifically in Col-0 with As stress. Kinases may act as signals on the transcription factors, leading to the production of stress proteins and secondary metabolites that can act as either damage-causing or stress-countering agents. Genes involved in mitogenactivated protein kinase (MAPK) and SNF1-related kinases (SnRKs) and leucine-rich repeat receptor-like kinase VIII (LRR-RLK VIII) pathways were more regulated in Col-0 than in Ws-2 by As stress (Additional file 1: Tables S2 and S7).

\section{Identification of putative candidate genes for As tolerance in Arabidopsis}

We aimed to isolate the Arabidopsis genes responsible for As tolerance. The microarray data corresponding to the 2 contrasting accessions and the dose-response effect were integrated to identify tolerance-associated genes. Accordingly, gene-filtering criteria were based on 2-fold change in gene expression in As-treated Col-0 versus Ws-2 (Col-0 $200 \mu \mathrm{M}$ As/Col-0 Control versus Ws-2 $100 \mu \mathrm{M}$ As/Ws-2 Control). Besides, a minimum 2-fold change in the doseresponse effect in Col-0 (200 $\mu \mathrm{M}$ As/Control versus 
$100 \mu \mathrm{M}$ As/Control) was included in the filtering criteria. We found 63 putative genes grouped according to biological processes by GO analysis (Table 2). These genes were further classified into regulatory genes, such as those encoding proteins responsible for signal transduction, transcriptional regulation, GTP binding and the proteasome-related pathway, and functional genes contributing to responses to heat, mitochondria electron transport and responses to oxidative, salt and other stresses (Table 2). We found 12 putative regulatory genes encoding the proteasome-related pathway associated with As tolerance (Table 2). These genes belong to various types of proteasome-related components such as RING/ U-box superfamily protein (AT1G14200), RING-H2 finger protein RHA1a (AT4G11370), ubiquitin fusion degradation UFD1 family protein (AT4G1542) and membrane-anchored ubiquitin-fold protein 4 (AT3G26980). In addition, tolerance to As was associated with the increased expression of genes related to heat stress, such as the heat-shock-protein 20-like chaperone superfamily protein (AT1G52560) and HSF B2A (AT5G62020).

A set of the tolerance-associated genes such as HSF $2 A$ (AT2G26150), HSF B2A (AT5G62020), ethylene response factor (AT2G33710), GT-like trihelix DNA-binding protein (AT1G76880), ATSDG37 (AT2G17900) and LRR-RLK VIII (AT3G09010) were selected for validation by semiquantitative reverse-transcription polymerase chain reaction (RT-PCR). The expression level of these genes was increased with As concentration in Col-0 (Figure 2c). In addition, the induction of the genes by As treatment was higher in Col-0 than in Ws-2. The regulation of these genes in response to As stress demonstrated the doesresponse and accession-specific effects. These results were consistent with the microarray data.

\section{Transcriptional characteristics of putative As-tolerance associated genes encoding LRR-RLK VIII}

Most of the As-tolerance associated genes were involved in signal transduction and regulatory mechanisms (47 out of 63, Table 2). Their up-regulation at the early stage endorsed the trigger of downstream components to cope with the stressful condition. These regulatory genes may act as the fate dominators of As tolerance. Very little is known about the role(s) of LRR-RLK VIII gene in regulation of plants responding to heavy metal stresses. To characterize an As tolerance-associated gene candidate encoding LRR-RLK VIII, we analyzed transcriptional regulation for Arabidopsis LRR-RLK VIII genes regarding its response to As stress. According to the microarray data, four genes (AT1G53430, AT1G53440, AT3G09010 and AT5G01950) belonging to the LRR-RLK VIII family were significantly upregulated by As stress (Table 2 and Additional file 1: Table S7). The data was further validated by semi-quantitative (Figure 3a). The expression level of the LRR-RLK VIII genes (AT1G53430, AT1G53440 and AT3G09010) was induced more significantly in Astreated Col-0 plants as compared to Ws-2. Next, we examined the expression of the $L R R-R L K$ VIII genes (AT1G53430, AT1G53440 and AT3G09010) in response to various stresses (Figure $3 \mathrm{~b}$ ). The gene expression was strongly induced in root tissues with treatment of $200 \mu \mathrm{M}$ As in comparison with $\mathrm{H}_{2} \mathrm{O}_{2}(100 \mu \mathrm{M})$ and $\mathrm{Cu}$ $(25 \mu \mathrm{M})$ stresses (Figure $3 \mathrm{~b})$. Therefore, the increase in LRR-RLK VIII gene expression was regulated in root tissues by As. The data demonstrated the specificity of the $L R R-R L K V I I I$ gene expression in response to As stress.

\section{Functional analysis of the LRR-RLK VIII gene in response to As stress using Arabidopsis T-DNA mutants}

To examine the function of an As tolerance-associated gene candidate encoding LRR-RLK VIII, we analyzed TDNA mutant lines for Arabidopsis LRR-RLK VIII genes regarding its response to As stress. Arabidopsis mutants with a T-DNA insertion in the locus coding for LRR-RLK VIII was characterized and subjected to As treatment (Figure 4a). The insertion of the mutant line (AT1G53440: SALK_057812) located 403 bp upstream of the start codon. The insertion abolished As-induced LRR-RLK VIII gene expression (Figure 4a). Two of the mutant lines for AT1G53440 (SALK_057812 and SALK_148231) showed alternation in As sensitivity (Figure 4b). At $200 \mu \mathrm{M}$, As significantly inhibited root elongation in both the wildtype plants and the LRR-RLK VIII mutants when compared to untreated controls (Figure $4 \mathrm{~b}$ ). However, the root growth inhibition was less in the LRR-RLK VIII mutant lines as compared to the wild-type plants. Thus, knockout of LRR-RLK VIII gene caused decrease in As sensitivity. The level of As concentration in roots was less in the LRR-RLK VIII mutant line (AT1G53440; SALK_057812) than wild-type plants (Figure 4c). In addition, the functional specificity of the $L R R-R L K V I I I$ gene was assessed by treatment of the Arabidopsis mutant lines with various stresses such as $\mathrm{As}, \mathrm{Cu}, \mathrm{Cd}, \mathrm{Zn}, \mathrm{H}_{2} \mathrm{O}_{2}$ and salt stress (Figure 4d and Additional file 3: Figure S2). Cu, Cd, $\mathrm{Zn}$, and salt stresses inhibited root growth to a similar level between wild-type plants and the LRR-RLK VIII mutant line (AT1G53440: SALK_057812). Alleviation of As- and $\mathrm{H}_{2} \mathrm{O}_{2-}$ induced root growth inhibition was observed in the $L R R-R L K$ VIII mutant line as compared to wild-type plants (Figure 4d). Thus, the loss-of-function mutation of LRR-RLK VIII caused As hyposensitivity, indicating its functional significance and specificity in response to As stress.

\section{Discussion}

Transcriptome profiling of As toxicity and tolerance

We aimed to compare changes at the physiological and global gene expression levels of Arabidopsis accessions 
Table 2 Selection of putative As tolerance-associated genes by comparing the expression ratio between the two accessions

\begin{tabular}{|c|c|c|c|}
\hline $\begin{array}{l}\text { AGI } \\
\text { number }\end{array}$ & Product encoded & $\begin{array}{l}\text { Tolerance ratio }^{a} \\
\text { Col-0 200/Ws-100 }\end{array}$ & $\begin{array}{l}\text { Dosage ratio }^{b} \\
\text { Col-0 200/100 }(\mu \mathrm{M})\end{array}$ \\
\hline \multicolumn{4}{|c|}{ Transcription factor } \\
\hline AT3G17611 & RHOMBOID-like protein 14 (RBL14) & 2.84 & 2.12 \\
\hline AT1G76880 & GT-like trihelix DNA-binding protein & 6.41 & 2.11 \\
\hline AT2G17900 & ATSDG37 & 3.39 & 2.50 \\
\hline AT5G62020 & Heat shock transcription factor B2A & 4.49 & 3.41 \\
\hline AT2G33710 & ERF (ethylene response factor) transcription factor family & 3.98 & 2.15 \\
\hline \multicolumn{4}{|c|}{ Responses to heat } \\
\hline AT5G59720 & ATHSP18.2 & 30.66 & 2.18 \\
\hline AT1G52560 & HSP20-like chaperones superfamily protein & 18.23 & 3.16 \\
\hline AT5G37670 & HSP20-like chaperones superfamily protein & 12.70 & 3.06 \\
\hline AT4G10250 & ATHSP22 & 8.58 & 3.84 \\
\hline AT5G15450 & HSP100/ClpB & 8.12 & 2.42 \\
\hline AT2G32120 & ATHSP70-2 & 4.51 & 2.89 \\
\hline AT4G25200 & AtHSP23.6 & 4.33 & 3.46 \\
\hline AT4G21320 & Heat-stress-associated 32-kD protein & 4.12 & 2.18 \\
\hline AT2G26150 & Heat shock transcription factor $\mathrm{A} 2$ & 3.79 & 3.98 \\
\hline AT2G25140 & HSP100/ClpB4 & 3.35 & 3.38 \\
\hline AT2G19310 & HSP20-like chaperones superfamily protein & 4.14 & 2.10 \\
\hline AT3G12050 & Aha1 domain-containing protein & 2.77 & 2.25 \\
\hline AT3G09350 & Encodes one of the Arabidopsis Hsp70-binding protein 1 & 4.12 & 2.39 \\
\hline AT2G24860 & DnaJ/Hsp40 cysteine-rich domain superfamily protein & 6.39 & 2.12 \\
\hline \multicolumn{4}{|c|}{ Responses to oxidative, salt and other stresses } \\
\hline AT4G37370 & CYP81D8, cytochrome P450 - like protein & 13.24 & 2.81 \\
\hline AT2G34500 & CYP710A1, putative cytochrome P450 & 5.73 & 2.66 \\
\hline AT1G73480 & alpha/beta-Hydrolases superfamily protein & 6.47 & 2.33 \\
\hline AT3G60140 & DIN2, member of glycoside hydrolase family 1 & 5.49 & 2.22 \\
\hline AT5G37710 & alpha/beta-Hydrolases superfamily protein & 3.33 & 2.25 \\
\hline AT3G09640 & ATAPX2 & 5.72 & 5.17 \\
\hline AT2G04040 & AtDTX1, identified as a detoxifying efflux carrier & 4.92 & 3.00 \\
\hline AT2G47710 & Adenine nucleotide alpha hydrolases-like superfamily & 2.35 & 2.09 \\
\hline \multicolumn{4}{|c|}{ Signal transduction } \\
\hline AT4G21390 & Protein serine/threonine kinase activity & 17.03 & 2.00 \\
\hline AT3G09010 & Protein kinase superfamily protein (LRR-RLK VIII) & 3.23 & 2.58 \\
\hline AT3G22840 & Encodes an early light-inducible protein & 2.38 & 2.05 \\
\hline AT2G21940 & Encodes a shikimate kinase & 3.62 & 2.37 \\
\hline AT2G20900 & diacylglycerol kinase 5 (DGK5) & 3.67 & 2.17 \\
\hline \multicolumn{4}{|c|}{ Proteasome related pathway } \\
\hline AT1G14200 & RING/U-box superfamily protein & 6.60 & 2.89 \\
\hline AT1G26800 & RING/U-box superfamily protein & 6.22 & 2.65 \\
\hline AT1G55530 & RING/U-box superfamily protein & 5.24 & 2.45 \\
\hline AT5G09800 & ARM repeat superfamily protein & 5.56 & 2.39 \\
\hline AT5G48655 & RING/U-box superfamily protein & 3.95 & 2.13 \\
\hline
\end{tabular}


Table 2 Selection of putative As tolerance-associated genes by comparing the expression ratio between the two accessions (Continued)

\begin{tabular}{|c|c|c|c|}
\hline AT3G13430 & RING/U-box superfamily protein & 3.75 & 2.28 \\
\hline AT4G11370 & Encodes a putative RING-H2 finger protein $\mathrm{RHA} 1 \mathrm{a}$ & 3.12 & 2.15 \\
\hline AT5G38895 & RING/U-box superfamily protein & 2.83 & 2.29 \\
\hline AT4G23570 & AtSGT1a & 3.56 & 2.49 \\
\hline AT4G15420 & Ubiquitin fusion degradation UFD1 family protein & 3.43 & 2.00 \\
\hline AT1G32940 & ATSBT3.5, involved in proteolysis & 3.65 & 2.05 \\
\hline AT3G26980 & MUB4, membrane-anchored ubiquitin-fold protein 4 & 4.88 & 2.54 \\
\hline \multicolumn{4}{|l|}{ GTP binding } \\
\hline AT3G21700 & ATSGP2, Monomeric G protein & 4.93 & 2.28 \\
\hline AT1G72660 & GTP1, Small GTP-binding protein & 16.12 & 3.01 \\
\hline \multicolumn{4}{|c|}{ Mitochondria electron transport } \\
\hline AT5G25450 & Cytochrome bd ubiquinol oxidase & 3.91 & 2.07 \\
\hline AT4G28390 & AAC3, ADP,ATP carrier-like protein & 10.16 & 2.57 \\
\hline AT4G27940 & manganese tracking factor for mitochondrial SOD2 (MTM1) & 2.65 & 2.70 \\
\hline \multicolumn{4}{|l|}{ Others } \\
\hline AT2G03430 & Ankyrin repeat family protein & 2.03 & 2.37 \\
\hline AT3G25900 & ATHMT-1, Homocysteine S-methyltransferase & 7.68 & 2.04 \\
\hline AT2G15490 & ATUGT7, putative glucosyltransferase & 4.86 & 2.07 \\
\hline AT4G00550 & UDP-galactose-dependent digalactosyldiacylglycerol synthase & 6.22 & 3.29 \\
\hline AT4G26270 & phosphofructokinase 3 (ATPFK3) & 5.38 & 3.64 \\
\hline AT3G16050 & Encodes a protein with pyridoxal phosphate synthase & 3.64 & 2.14 \\
\hline AT1G30070 & SGS domain-containing protein & 3.53 & 2.26 \\
\hline AT5G64170 & dentin sialophosphoprotein-related protein & 3.29 & 2.34 \\
\hline AT3G57810 & Cysteine proteinases superfamily protein & 2.94 & 2.27 \\
\hline AT1G24090 & RNase $\mathrm{H}$ family protein & 2.90 & 2.24 \\
\hline AT2G16900 & Arabidopsis phospholipase-like protein family & 2.80 & 2.08 \\
\hline AT4G32440 & Plant Tudor-like RNA-binding protein & 2.40 & 2.28 \\
\hline AT1G67360 & Rubber elongation factor protein & 2.24 & 2.73 \\
\hline
\end{tabular}

${ }^{\mathrm{a}} \mathrm{Col}-0$ 200/Ws-100 refers to pair-wise comparison of expression ratio (Col-0 $200 \mu \mathrm{M}$ As vs Col-0 Control) / (Ws-2 $200 \mu \mathrm{M}$ As vs Ws-2 Control).

${ }^{b} \mathrm{Col}-0$ 200/100 refers to pair-wise comparison of expression ratio (Col-0 $200 \mu \mathrm{M}$ As vs Col-0 Control) / (Col-0 $100 \mu \mathrm{M}$ As vs Col-0 Control).

tolerant and sensitive to As stress. Arabidopsis Col-0 accession plants were more tolerant to As stress than Ws2 plants and accumulated significantly less As in root tissues. Microarray assay identified the early response of Arabidopsis to As stress and possible differences in the mechanisms to achieve tolerance in the accessions. GO analysis of the transcriptome data suggested that As stress significantly affects biological processes related to responses to heat, oxidative stress, metal ion and cell wall organization, and cytokinin and transport in both accessions. The differential expression levels of ABAand ethylene-related genes may contribute to the As sensitivity and tolerance of the two accessions. Pathway analysis suggested that the As tolerance of the Col-0 accession was attributed to enhanced expression of regulatory and functional components such as proteasome- related mechanisms and responses to heat. The present work extends current knowledge of early transcriptional regulation by As stress in Arabidopsis roots and provides valuable insights into aspects of As toxicity, detoxification and acquired tolerance.

\section{Ecotypic variation in As tolerance}

Toxicity and tolerance to heavy metals are closely related to the accumulation of heavy metals in plant tissues $[9,16,27]$. Plant species and even genotypes differ greatly in their ability to take up, transport and accumulate heavy metals. In maize, an Al-tolerant genotype accumulated significantly less $\mathrm{Al}$ in root tips than the Al-sensitive genotype [28]. Holcus lanatus has As-tolerant and -sensitive accessions, and relatively less As concentration accumulated in roots of As-tolerant accessions [23]. 


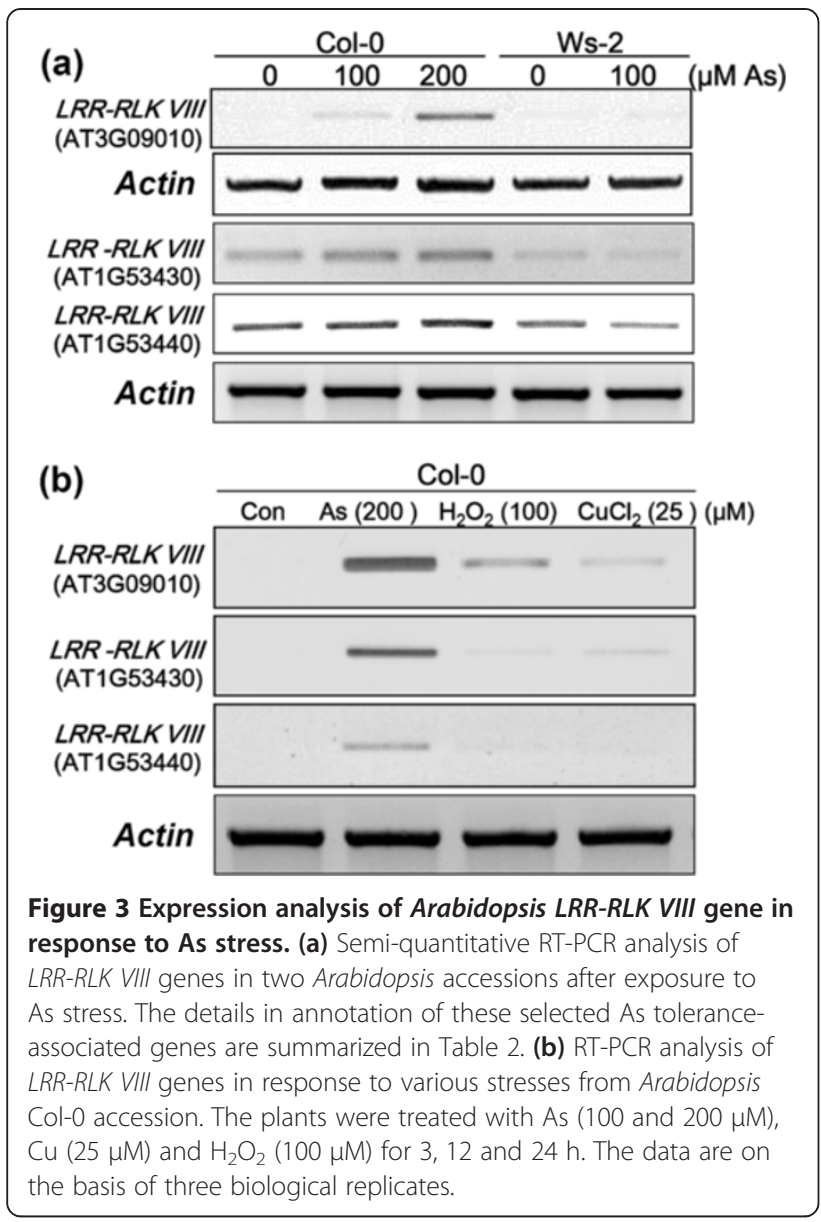

We selected Arabidopsis with different accessions to study As tolerance by root growth inhibition (Figures $1 \mathrm{a}$ and $\mathrm{b}$ ) and As accumulation (Figure 1c). The Arabidopsis accession Col-0 was more tolerant to As stress than Ws-2 and accumulated less As in root tissues (Figure 1c). An As exclusion mechanism may operate in roots of As-tolerant Col-0. In As-sensitive Ws-2 plants, As toxicity was associated with relatively higher accumulation of As in roots (Figure 1). GO analysis of microarray data also suggested that the increased As accumulation of Ws-2 resulted in enhanced expression of toxin and osmotic stress-related genes (Table 1). Therefore, the ecotypic variation in As tolerance appeared to be associated with As level, as well as expression of toxin and osmotic stress-related genes.

\section{Comparisons of short- and long-term transcriptome responses to As stress}

The transcriptional response of Arabidopsis Col-0 to As (V) stress has been reported [10]. As may induce genes involved in response to oxidative stress and repress that of genes induced by phosphate starvation [10]. The cysteine-rich metal-binding protein metallothionein (MT) was also induced. Previous work examined As toxicity in Arabidopsis in terms of root growth inhibition and transcriptional responses after 3 and $10 \mathrm{~d}$ [10]. Forty-six and 113 genes were induced and repressed, respectively. The physiological and metabolic parameters measured under these long treatment periods might be distorted by the severe toxic effects of As. Mechanisms of adaptation after long-term exposure are relevant. However, we aimed to understand the primary response to metal ion exposure as opposed to responses to unspecific cellular damage. Increased transcript abundance of heat shock protein and the ubiquitin-proteasome pathway (as reported in this study) are general responses to cellular stress and damage. We examined genomic gene expression profiles and biological pathways in Arabidopsis in response to short-term As stress (Figures 3 and 4): 1.5 and $3 \mathrm{~h}$ of As exposure resulted in 2451 and 1149 As-responsive genes in Col-0 and Ws-2, respectively. Only 16 genes were regulated in common after long-term [10] and short-term (this study) As exposure (Additional file 1: Table S8). Genes that have previously been reported to be As inducible or pathways were not affected by short-term As exposure (Table 1). We did not observe changes in expression of MT genes, which suggests a unique cellular response to short-term As exposure. Transcriptome data demonstrated that As stress significantly affects biological processes related to responses to heat, oxidative stress, metal ion, cell wall organization and cytokinin, as well as transport (Table 1). Therefore, Arabidopsis plants rapidly and simultaneously change the expression of specific sets of genes to cope with As stress in root tissues.

\section{As-responsive genes involved in the detoxification}

Plants possess a range of potential cellular mechanisms that may be involved in the detoxification of heavy metals such as antioxidant and transporter systems [29,30]. Genes coding for proteins involved in oxidative stress such as thioredoxins and Class III peroxidase were highly represented in our microarray data of Arabidopsis plants exposed to As stress (Additional file 1: Table S2). Transcripts belonging to GST formed the largest group within the oxidative stress-related genes. Most of these transcripts are in the Tau subfamily (GST-Tau), and the remaining sequences are similar to the Phi and lambda subfamily (Additional file 1: Table S3). GSTs are induced by a number of intracellular and environmental factors such as oxidative stress and heavy metals $[31,32]$ and are involved in detoxification of both endogenous and xenobiotic compounds with electrophilic centers by the nucleophilic addition of glutathione [31]. Some isoforms of GST show dual activity, additionally functioning as a glutathione peroxidase in the presence of reactive oxygen species [31]. This phenomenon provides further evidence for the role of GSTs in antioxidant metabolism. As-glutathione conjugates may be produced by GSTs in animal cells such as rat liver [15,33,34]. However, GST-mediated conjugation of 


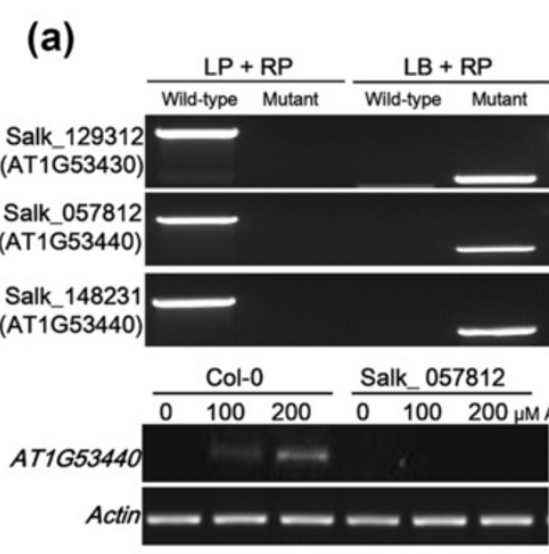

(c)

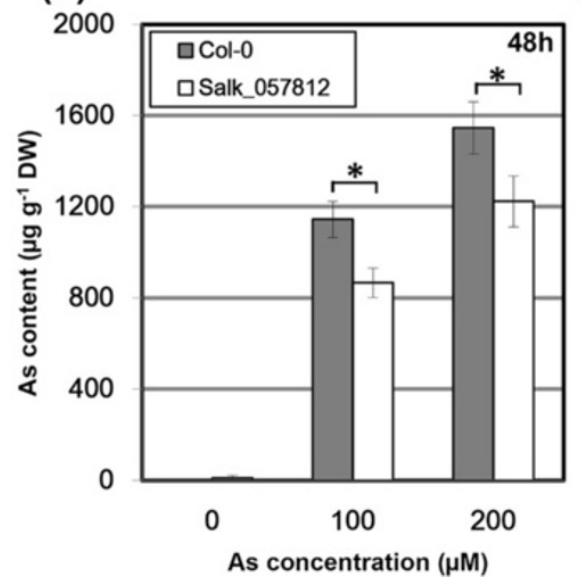

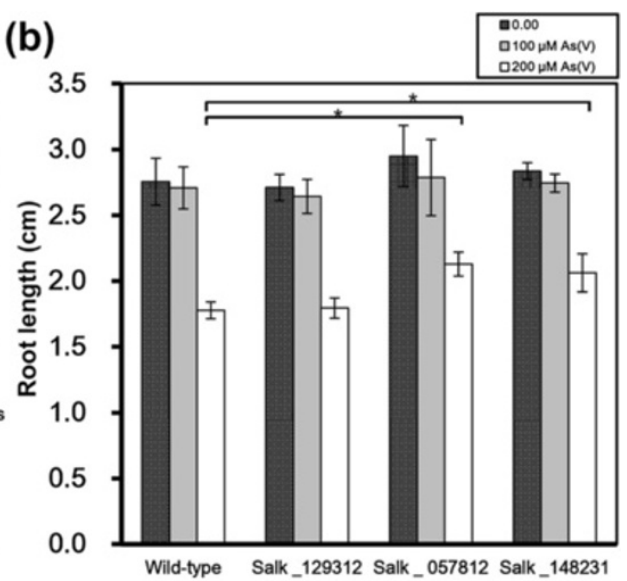

(d)

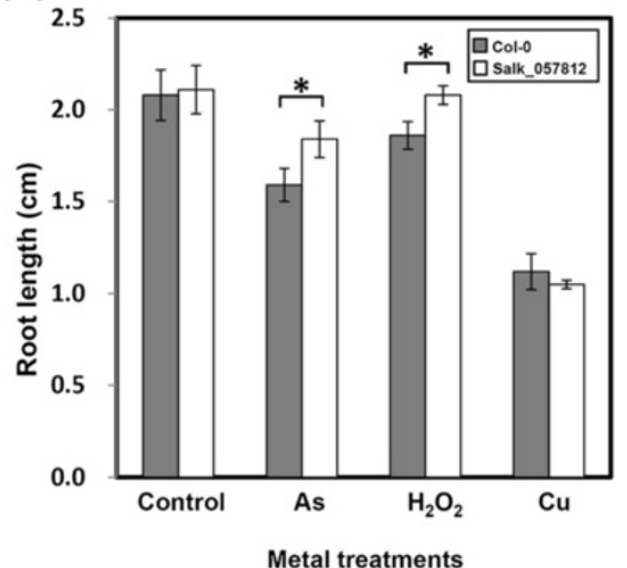

Figure 4 Functional analysis of a tolerance-associated gene encoding LRR-RLK VIII in response to As stress. (a) Identification of T-DNA insertion for $L R R-R L K$ VIII mutations in the Arabidopsis genome by PCR Analysis. The left (LB) border primers for T-DNA insertion, and the left (LP) and right (RP) genomic primers for LRR-RLK VIII genes are presented in materials and methods. The sequences of junctions between T-DNA borders and the genomic target were detected in homologous LRR-RLK VIII mutants when compared to the wild-type plants. Two T-DNA mutant lines for locus AT1G53440 were characterized, and one for AT1G53430 (upper panel). The gene expression of LRR-RLK VIII (AT1G53440) in the mutant line (Salk_057812) was analyzed by RT-PCR (bottom panel). There was no characterized T-DNA mutant line for AT3G09010. (b) Effect of As (V) on the root elongation of Arabidopsis wild-type and LRR-RLK VIII mutant lines was assessed. Measurement of root elongation was similar to that described in Figure 1. Seedlings were grown on quarter-strength MS medium for $4 \mathrm{~d}$ and then transferred to medium with 100 and $200 \mu \mathrm{M}$ As $(V)$ and grown for an additional $4 \mathrm{~d}$. As tolerance was determined by relative root growth after treatment. Root length of plants was measured after treatment with As. Root samples were collected from 3 independent experiments (each from a pool of 7 root samples). Data are mean \pm SD. *P $\leq 0.05$ compared to As treatment $(200 \mu \mathrm{M})$ from wild-type plants. The difference in root elongation is significant according to Student's t test. (c) Accumulation of As ( $V$ ) by Arabidopsis wild-type and LRR-RLK VIII mutant lines was analyzed with the methods similar to Figure 1. Data are mean \pm SD calculated from 3 biological replicates per treatment. *P $\leq 0.05$ compared with wild-type plants. (d) Effect of As (200 $\mu \mathrm{M})$, Cu (50 $\mu \mathrm{M})$ and $\mathrm{H}_{2} \mathrm{O}_{2}(100 \mu \mathrm{M})$ on the root elongation of Arabidopsis wild-type and LRR-RLK VIII mutant lines. Measurement of root elongation was similar to that described in Figure 1. At least three biological replicates were performed corresponding to each treatment. Data are the mean \pm SE of three independent replicates.

glutathione with As has not been demonstrated in plants. The upregulation of Tau class GSTs has also been noted in transcriptomic and proteomic analysis of plant roots under As stress $[9,32]$. Thus, our results suggest that the Tau class of GSTs most likely functions at the root level to protect cells against heavy-metal--induced oxidative damage. In addition, we found differential regulation of genes encoding GSTs between As-tolerant and -sensitive Arabidopsis accessions (Additional file 1: Table S2), with fewer
As-induced GST genes regulated in As-tolerant Col-0 than As-sensitive Ws-2, which indicates the differential GSTbased detoxification. The GST gene expression profile can therefore account for the tolerant Arabidopsis Col-0 accession being less affected by As stress.

As-tolerance associated genes involved in ethylene signalling The hormones ethylene participates in signaling cascades regulating both development and responses to 
stress [35]. Recently, cross-talk between ethylene signaling and sulfur assimilation in plants has been proposed [36]. It was demonstrated that sulfur can induce tolerance to $\mathrm{Cd}$ stress and alleviate photosynthetic inhibition through ethylene by maintaining high GSH levels [37]. However, their roles in Arabidopsis exposed to As has not been reported. In this study, genes coding for ethylene-signalling components were significantly enriched in As-tolerant Col-0 with short-term As exposure (Table 1 and Additional file 1: Table S2). The transcription factor gene encoding ERF (ethylene response factor) was identified as an Astolerance associated gene (AT2G33710) (Table 2). The sulfur assimilation pathway was also affected by As stress (Additional file 2: Figure S1). Thus, regulatory interaction between sulfur assimilation and ethylene may contribute to tolerance to As in Col-0 accession. Furthermore, the predominant functional themes of the tolerance-associated genes are related to the ubiquitin/proteasome pathway and responses to heat (Table 2). These molecular signatures identified in the As-responsive transcriptome might work in concert for tolerance to As stress. A number of studies have suggested a role for ethylene in plants on exposure to heavy metals. For example, cadmium or copper induces the biosynthesis of ethylene in various plant species $[38,39]$. The hormone is transmittable signals, which invoke stress responses and tolerance in the shoot $[40,41]$. In this study, foliar necrosis was less severe in As-tolerant Col-0 than As-sensitive Ws-2 after exposure to As for 1 week (Additional file 4: Figure S3).

\section{As-tolerance associated genes involved in ubiquitin/ proteasome pathways}

The elevated expression of genes related to the proteasome pathway indicated that the oxidized or As-bound proteins in As stressed plant cells might be ubiquitinated for proteasome-mediated degradation. Expression levels of the components and intermediates of the ubiquitin/proteasome pathway were predominately induced in the Col- 0 accession and identified as tolerant-associated genes under As stress (Table 2). A notable number of the proteasomerelated genes belong to the component of E2 and E3 ubiquitin ligases (E3s) such as RING/U-box superfamily protein, RING-H2 finger protein and membrane-anchored ubiquitin-fold protein (Table 2). In addition, the ubiquitinassociated proteins present contained the ubiquitin fusion degradation UFD1 family protein. These are key intermediates in the tagging of proteins for proteasomal degradation. RING proteins can act as single components containing both the active site and the binding pocket for the E2ubiquitin intermediate [42-44]. Emerging evidence suggests the potential roles of the proteasome-mediated pathway in plants with As exposure. Expression profiling of Crambe abyssinica under As stress identified gene networks involved in $20 \mathrm{~S}$ proteasome degradation [27]. In Lemna minor, the response to As (III) involves cellular proteasechaperone machineries, including heat shock protein synthesis and the ubiquitin/proteasome pathway [45]. In addition, the As-tolerance associated genes identified in this study (Table 2) were compared with $\mathrm{Cd}$-induced genes in Arabidopsis [46]. Gene encoding ubiquitin-specific protease (AT3G28220) was induced by short-term Cd treatment, indicating the roles of ubiquitin/proteasome pathways in heavy metal stress. Therefore, our results suggest that the proteasome-mediated protein degradation machinery is vital for As tolerance in plants.

\section{Potential roles of the As-tolerance associated genes encoding LRR-RLKs}

RLKs consist of extracellular repeats that are linked by a transmembrane domain to either an intracellular adapter domain or a kinase domain [47]. LRR-RLKs represent the largest subfamily in the Arabidopsis genome with approximately 235 members, divided over 13 subfamilies (LRR I to XIII) [48]. The biological functions have been defined for only about 30 proteins, which play crucial roles in a variety of different physiological processes such as development, pathogen resistance and hormone perception [47]. In addition, it has been reported that target genes of the Cd-responsive miRNAs encode LRR-RLKs [49]. Exploration of Arabidopsis expression data with the Arabidopsis eFP Browser [50] revealed the LRR-RLK VIII genes were upregulated by salt and cold stresses (Additional file 5: Figure S4). Functional characterization of the LRRRLK VIII gene (AT1G53430) using a T-DNA insertion line showed that the mutant was resistance to salt stress [48]. In this study, four genes (AT1G53430, AT1G53440, AT3G09010 and AT5G01950) belonging to the LRR-RLK VIII family were significantly upregulated by As stress in the tolerant Col- 0 accession (Table 2 and Additional file 1: Table S7). The result was further validated by semiquantitative and real-time RT-PCR analysis (Figure 3). Some members of the LRR-RLK VIII family may be functionally redundant in the regulation of As stress (Figure 4). Two of the mutant lines (AT1G53440: SALK_057812 and SALK_148231) showed alternation in As sensitivity and the metal accumulation (Figure 4). Thus, this study revealed a novel role for LRR-RLK VIII in sensitivity to As stress. Some mammalian toll-like receptors, which are the counterparts of plant LRR-RLKs, are involved in xenobiotic response such as drug metabolism [51,52]. It may be speculated that specific plant LRR-RLKs could have evolved into sensors under heavy metal stress.

\section{LRR-RLK VIII may involve in perception of As stress leading alternation in As sensitivity}

In this study, we report the functional analysis of an Arabidopsis LRR-RLK VIII gene involved in the regulation of early root responses to As stress. The Arabidopsis 
LRR-RLK VIII mutants alleviated As-induced root growth inhibition, indicating that the mutant roots may be less sensitive to the heavy metal stress (Figure 4b). Accumulation of As level was decreased in the LRR-RLK VIII mutants as compared to wild-type plants (Figure 4c). It is suggested that the $L R R-R L K V I I I$ mutants are less sensitive to As stress due to reduced As accumulation in roots. Therefore, the LRR-RLK VIII gene appeared to function as a negative regulator of As tolerance. Similarly, knocking out expression of a Medicago truncatula LRR-RLK (Srlk) by TILLING failed to limit root growth when exposed to salt stress [53]. These $L R R-R L K$ mutant plants accumulate fewer sodium ions than controls, and several early saltregulated genes are downregulated after exposure to salt stress [53]. Taken together, the results may link the LRRRLK receptor with perception of As stress and activation of a signaling pathway leading to alternation in As sensitivity.

\section{Conclusions}

We performed a comparative investigation to reveal changes in gene expression that take place in roots of an As-tolerant and As-sensitive accessions of Arabidopsis under short-term As stress. We identified putative candidate genes for As tolerance in Arabidopsis to explore molecular mechanisms in response to As. Future studies involving Arabidopsis mutants or overexpressors with altered expression of these genes will be helpful to elucidate their biological significance and to clarify new pathways involved in As toxicity and tolerance. Analysis of As tolerance by quantitative trait locus (QTL) strategies in successive generations obtained from crosses between the two accessions will facilitate the identification of genes involved in As tolerance. The knowledge of how plants acquire tolerance to As is essential for developing novel strategies for efficient phytoremediation and As tolerant crops.

\section{Methods}

Plant materials and growth conditions

Arabidopsis thaliana Col-0 (accession no. CS22625) and Ws-2 (no. CS22659) were obtained from the Arabidopsis Biological Resource Center (Ohio State University, USA) and propagated for 1 generation. The seeds were vernalized for $2 \mathrm{~d}$ at $4^{\circ} \mathrm{C}$ before germination. About 500 seeds were sterilised by $10 \mathrm{~min}$ of incubation in $1 \mathrm{ml}$ of $1.2 \%$ (v/v) sodium hypochlorite solution with a few drops of Tween 20, then rinsed 4 times with sterilized water. Surface-sterilized seeds were sown on quarter-strength MS (Murashige-Skoog) medium (M0222.0050, Duchefa Biochemie, The Netherlands) supplemented with $1.0 \%(\mathrm{w} / \mathrm{v}) \mathrm{su}-$ crose, $\mathrm{pH} 5.7$, with $0.05 \%$ (w/v) 2-morpholinoethanesulfonic acid monohydrate, and solidified with $1 \%(\mathrm{w} / \mathrm{v})$ phytagel (Sigma, St. Louis, MO, USA). Seedlings were grown under 16-hr white light/8-hr dark at $25^{\circ} \mathrm{C}$ with an illumination intensity of 3,000 Lux by placing the Petri dish vertically.

\section{Measurement of root length}

Seven 4-d-old seedlings were transferred to plates $(12 \times$ $12 \times 1.7 \mathrm{~cm}$ ) with medium supplemented with As from 100 to $300 \mu \mathrm{M}$. Control seedlings were incubated without As. Seedlings were allowed to grow for additional $2 \mathrm{~d}$. The elongation of primary roots was measured by manually recording on the plate. Data were obtained from 3 biological replicates.

\section{Determination of As concentration in roots}

After $3 \mathrm{~h}$ or $48 \mathrm{~h}$ of As treatment, roots of 4-d-old Arabidopsis seedlings were rinsed thoroughly with distilled water and oven dried for $2 \mathrm{~d}$ at $60^{\circ} \mathrm{C}$, then digested in $\mathrm{HNO}_{3} / \mathrm{H}_{2} \mathrm{O}_{2}, 3: 2(\mathrm{v} / \mathrm{v})$, for $30 \mathrm{~min}$. As concentration was determined by inductively coupled plasma atomic emission spectrometry (ICP-AES) (HORIBA Jobin Yvon 20002 , France). Data were mean values from 3 independent biological replicates.

\section{RNA extraction}

The medium was overlaid with a layer of nylon mesh and 4-d-old Arabidopsis seedlings grew on the nylon mesh to facilitate collection of root samples. Total RNA was isolated from roots with use of an RNeasy Plant Mini Kit (Qiagen, Hilden, Germany), treated with DNase (Roche, Germany) to eliminate genomic DNA contamination, then purified and concentrated by use of the RNeasy MinElute Cleanup Kit (Qiagen). Three biological replicates were grown in the same growth chamber to minimize experimental and sample-to-sample variation. For each accession, total RNA samples extracted from untreated (control) and As-treated (experimental) samples were subjected to microarray analysis.

\section{Microarray analysis}

Microarray analysis involved Affymetrix microarrays (GeneChip Arabidopsis ATH1 genome array) containing 22,810 probe sets on a single chip. The data were analyzed by use of the Microarray Suite v5.0 with Affymetrix default settings and global scaling as the normalization method. The trimmed mean target intensity of each array was arbitrarily set to 100 . The raw cell intensity data files (GeneChip CEL files) were analyzed by use of GeneSpring GX10 (Agilent Technologies, CA, USA). Data were normalized by the GeneChip RMA Robust Multichip Average (GC-RMA) algorithm and converted to $\log _{2}$ scale to allow for comparing the 3 biological replicates. As treated sample was compared to an untreated control sample harvested from each accession. Genes with statistically significant 2 -fold change in expression in all experiments were detected by Student's $t$ test at $\mathrm{P}<0.05$. The Benjamini and 
Hochberg algorithm calculates false discovery rates (FDRs) that are inherently corrected for multiple testing [25]. Genes were considered as significantly up- or downregulated if the FDR value for the corresponding probe set was $<0.05$. We focused our attention on the subset of these transcripts that differed by 2 - fold between As-treated and untreated samples. Three biological replicates of each sample were carried out to achieve reproducibility of the chip hybridization. The microarray data have been deposited in Gene Expression Omnibus (no. GEO: GSE31977).

\section{Gene ontology (GO) analysis}

The differentially expressed genes were classified by biological function by analysis with agriGO (http://bioinfo. cau.edu.cn/agriGO/) [54] and MapMan [55]. The gene lists in each functional categories were obtained from The Arabidopsis Information Center (http://www.arabidopsis.org/) and Arabidopsis thaliana Kinase Database (http://bioinformatics.cau.edu.cn/athKD/index.htm).

\section{Semi-quantitative RT-PCR}

First-strand cDNA was synthesized from $2 \mu \mathrm{g}$ of total RNA with $1 \mu \mathrm{l}$ oligo (dT) 15 primers by use of the ImProm-II Reverse Transcription System (Promega, WI, USA). The fragments of cell cycle-related genes were amplified by use of gene-specific primers (Additional file 6: Table S9). Actin was an internal control. The PCR cycling involved an initial denaturation step at $94^{\circ} \mathrm{C}$ for $2 \mathrm{~min}, 27-40$ cycles of amplification and a final elongation step at $72^{\circ} \mathrm{C}$ for $5 \mathrm{~min}$. PCR products were analyzed on a $2 \%(\mathrm{w} / \mathrm{v})$ agarose gel. The experiments were repeated at least 2 times for each gene.

\section{Characterization of Arabidopsis LRR-RLK VIII T-DNA insertion mutants}

The Arabidopsis LRR-RLK VIII T-DNA mutant lines (AT1G53430, SALK_129312; AT1G53440, SALK_148231 and SALK_057812; AT3G09010, SALK_019665) were obtained from Arabidopsis Biological Resource Center (ABRC; http://abrc.osu.edu/resources). The DNA samples were extracted from wild-type and LRR-RLK VIII T-DNA mutant lines and subject to PCR analysis. Homozygous plants were verified with $L R R$-RLK VIII-specific primers spanning the T-DNA insertion site (LP and RP) together with a T-DNA left-border primer (LB) (Additional file 6: Table S9). The PCR consisted of an initial denaturation step at $94^{\circ} \mathrm{C}$ for $2 \mathrm{~min}, 30$ cycles of amplification with annealing temperature at $55^{\circ} \mathrm{C}$ and a final elongation step at $72^{\circ} \mathrm{C}$ for $5 \mathrm{~min}$. The PCR product was separated on a $2 \%(\mathrm{w} / \mathrm{v})$ agarose gel. The amplified PCR fragments were sequenced to confirm the presence of a $L R R-R L K$ VIII sequence and to determine the T-DNA insertion site.

\section{Additional files}

Additional file 1: Table S1-S8. List of genes, expression intensity, and p-values corresponding to microarray data.

Additional file 2: Figure S1. Transcriptional changes of genes involved in sulfur assimilation, cysteine biosynthesis and phytochelatin synthesis in As-treated roots.

Additional file 3: Figure S2. Effects of $\mathrm{NaCl}(20 \mathrm{mM}), \mathrm{CuCl} 2(25 \mu \mathrm{M})$, ZnSO4 $(200 \mu \mathrm{M})$ and $\mathrm{CdCl} 2(100 \mu \mathrm{M})$ on the root elongation of Arabidopsis wild-type and LRR-RLK VIII mutant lines was assessed.

Additional file 4: Figure S3. Effects of As on the growth of shoots in 2 Arabidopsis accessions.

Additional file 5: Figure S4. Exploring Arabidopsis gene expression data with the (a) eFP Browser (http://www.bar.utoronto.ca/) [50] and (b) CAU Bioinformatic Center (http://bioinformatics.cau.edu.cn/cgi-bin/ gbrowse/arabidopsis/).

Additional file 6: Table S9. List of primers used in this study.

\section{Abbreviations}

ABA: Absicisc acid; As: Arsenic; CK: Cytokinin; ET: Ethylene; GST: Glutathione S-transferase; LRRs-RLK: Leucine-Rich Repeats receptor like kinase; GO: Gene ontology; HSP: Heat shock protein; HSF: Heat shock transcription factor; PC: Phytochelatin; ABA: Abscisic acid; ABC: ATP-binding cassette; MATE: Multidrug and toxic compound extrusion; MAPK: Mitogen-activated protein kinase; MT: Metallothioneins; OPT: Oligopeptide; SnRK: Snf1-related kinases.

\section{Competing interest}

The authors declare that they have no competing interests.

\section{Authors' contributions}

PYC, TTQN, GRZ and TLH designed the experiments, conducted microarray experiments, performed bioinformatic analysis and wrote the manuscript. SFF and $\mathrm{HJH}$ contributed to interpretation of the data, manuscript writing and modification. CYL and LYH contributed to analysis of relationship between hormone homeostasis in response to As stress. All authors read and approved the manuscript.

\section{Acknowledgements}

This study was funded by grants from the Taiwan National Science Council (project number NSC 98-2621-B-006-003-MY3). This work was also supported by a grant from the Ministry of Education, Taiwan (Aim for the Top University Project D100-38B05). The Affymetrix GeneChip assays were performed by the Affymetrix Gene Expression Service Lab (http://ipmb.sinica.edu.tw/affy/), supported by Academia Sinica, Taiwan. Expression profiles and data mining involved a system provided by the Bioinformatics Core for Genomic Medicine and Biotechnology Development at the National Cheng Kung University, supported by a National Science Council grant (NSC 97-3112-B006-011).

\section{Author details}

${ }^{1}$ Department of Biology, National Chunghua University of Education, No.1, Jin-De Road, 500, Changhua, Taiwan. '2Department of Life Sciences, National Cheng Kung University, No.1 University Road 701, Tainan, Taiwan.

Received: 12 July 2013 Accepted: 31 March 2014

Published: 16 April 2014

\section{References}

1. Zhao FJ, McGrath SP, Meharg AA: Arsenic as a Food Chain Contaminant: Mechanisms of Plant Uptake and Metabolism and Mitigation Strategies. Annu Rev Plant Biol 2010, 61:535-559.

2. Zhu YG, Sun GX, Lei M, Teng M, Liu YX, Chen NC, Wang LH, Carey AM, Deacon C, Raab A, Meharg AA, Williams PN: High percentage inorganic arsenic content of mining impacted and nonimpacted Chinese rice. Environ Sci Technol 2008, 42:5008-5013.

3. Bhattacharjee $Y$ : Toxicology: a sluggish response to humanity's biggest mass poisoning. Science 2007, 315:1659-1661. 
4. Carbonell-Barrachina AA, Signes-Pastor AJ, Vazquez-Araujo L, Burlo F, Sengupta B: Presence of arsenic in agricultural products from arsenicendemic areas and strategies to reduce arsenic intake in rural villages. Mol Nutr Food Res 2009, 53:531-541.

5. Williams PN, Islam MR, Adomako EE, Raab A, Hossain SA, Zhu YG, Feldmann J, Meharg AA: Increase in rice grain arsenic for regions of Bangladesh irrigating paddies with elevated arsenic in groundwaters. Environ Sci Technol 2006, 40:4903-4908.

6. Wei CY, Chen TB: Arsenic accumulation by two brake ferns growing on an arsenic mine and their potential in phytoremediation. Chemosphere 2006, 63:1048-1053.

7. Zheng MZ, Cai C, Hu Y, Sun GX, Williams PN, Cui HJ, Li G, Zhao FJ, Zhu YG: Spatial distribution of arsenic and temporal variation of its concentration in rice. New Phytol 2011, 189:200-209.

8. Tripathi RD, Srivastava S, Mishra S, Singh N, Tuli R, Gupta DK, Maathuis FJ: Arsenic hazards: strategies for tolerance and remediation by plants. Trends Biotechnol 2007, 25:158-165.

9. Norton GJ, Lou-Hing DE, Meharg AA, Price AH: Rice-arsenate interactions in hydroponics: whole genome transcriptional analysis. J Exp Bot 2008, 59:2267-2276

10. Abercrombie JM, Halfhill MD, Ranjan P, Rao MR, Saxton AM, Yuan JS, Stewart CN Jr: Transcriptional responses of Arabidopsis thaliana plants to As (V) stress. BMC Plant Biol 2008, 8:87.

11. Srivastava S, Srivastava AK, Suprasanna P, D'Souza SF: Comparative biochemical and transcriptional profiling of two contrasting varieties of Brassica juncea $\mathrm{L}$. in response to arsenic exposure reveals mechanisms of stress perception and tolerance. J Exp Bot 2009, 60:3419-3431.

12. Rahman F, Naidu R: The influence of arsenic speciation (AsIll \& AsV) and concentration on the growth, uptake and translocation of arsenic in vegetable crops (silverbeet and amaranth): greenhouse study. Environ Geochem Health 2009, 31(Suppl 1):115-124.

13. Oremland RS, Stolz JF: The ecology of arsenic. Science 2003, 300:939-944.

14. Mendoza-Cozatl DG, Jobe TO, Hauser F, Schroeder Jl: Long-distance transport, vacuolar sequestration, tolerance, and transcriptional responses induced by cadmium and arsenic. Curr Opin Plant Biol 2011, 14:554-562.

15. Ali W, Isayenkov SV, Zhao FJ, Maathuis FJ: Arsenite transport in plants. Cell Mol Life Sci 2009, 66:2329-2339.

16. Bleeker PM, Hakvoort HW, Bliek M, Souer E, Schat H: Enhanced arsenate reduction by a CDC25-like tyrosine phosphatase explains increased phytochelatin accumulation in arsenate-tolerant Holcus lanatus. Plant J 2006, 45:917-929.

17. Liu $X$, Zhang $S$, Shan $X Q$, Christie $P$ : Combined toxicity of cadmium and arsenate to wheat seedlings and plant uptake and antioxidative enzyme responses to cadmium and arsenate co-contamination. Ecotoxicol Environ Saf 2007, 68:305-313.

18. Briat JF: Arsenic tolerance in plants: "Pas de deux" between phytochelatin synthesis and ABCC vacuolar transporters. Proc Natl Acad SCi U S A 2010, 107:20853-20854.

19. Clemens S: Toxic metal accumulation, responses to exposure and mechanisms of tolerance in plants. Biochimie 2006, 88:1707-1719.

20. Ma JF, Yamaji N, Mitani N, Xu XY, Su YH, McGrath SP, Zhao FJ: Transporters of arsenite in rice and their role in arsenic accumulation in rice grain. Proc Natl Acad Sci U S A 2008, 105:9931-9935.

21. Da Silva NA, Shah D, Shen MWY, Chen W: Enhanced arsenic accumulation in Saccharomyces cerevisiae overexpressing transporters Fps1p or Hxt7p. J Biotechnol 2010, 150:101-107.

22. Lou-Hing D, Zhang B, Price AH, Meharg AA: Effects of phosphate on arsenate and arsenite sensitivity in two rice (Oryza sativa L.) cultivars of different sensitivity. Environ Exp Bot 2011, 72:47-52.

23. Quaghebeur M, Rengel Z: The distribution of arsenate and arsenite in shoots and roots of Holcus lanatus is influenced by arsenic tolerance and arsenate and phosphate supply. Plant Physiol 2003, 132:1600-1609.

24. Chakrabarty D, Trivedi PK, Misra P, Tiwari M, Shri M, Shukla D, Kumar S, Rai A, Pandey A, Nigam D, Tripathi RD, Tuli R: Comparative transcriptome analysis of arsenate and arsenite stresses in rice seedlings. Chemosphere 2009, 74:688-702.

25. Benjamini Y, Hochberg Y: Controlling the False Discovery Rate - a Practical and Powerful Approach to Multiple Testing. J R Stat Soc Series B 1995, 57:289-300

26. Dixon DP, Cummins L, Cole DJ, Edwards R: Glutathione-mediated detoxification systems in plants. Curr Opin Plant Biol 1998, 1:258-266.
27. Paulose B, Kandasamy S, Dhankher OP: Expression profiling of Crambe abyssinica under arsenate stress identifies genes and gene networks involved in arsenic metabolism and detoxification. BMC Plant Biol 2010, 10:108.

28. Giannakoula A, Moustakas M, Syros T, Yupsanis T: Aluminum stress induces up-regulation of an efficient antioxidant system in the Al-tolerant maize line but not in the Al-sensitive line. Environ Exp Bot 2010, 67:487-494.

29. Hall JL: Cellular mechanisms for heavy metal detoxification and tolerance. J Exp Bot 2002, 53:1-11.

30. Clemens S: Molecular mechanisms of plant metal tolerance and homeostasis. Planta 2001, 212:475-486.

31. Marrs KA: The Functions and Regulation of Glutathione S-Transferases in Plants. Annu Rev Plant Physiol Plant Mol Biol 1996, 47:127-158.

32. Ahsan N, Lee DG, Alam I, Kim PJ, Lee JJ, Ahn YO, Kwak SS, Lee IJ, Bahk JD, Kang KY, Renaut J, Komatsu S, Lee BH: Comparative proteomic study of arsenicinduced differentially expressed proteins in rice roots reveals glutathione plays a central role during As stress. Proteomics 2008, 8:3561-3576.

33. Martinez-Finley EJ, Aschner M: Revelations from the Nematode Caenorhabditis elegans on the Complex Interplay of Metal Toxicological Mechanisms. J Toxicol 2011, 2011:895236.

34. Liu J, Chen H, Miller DS, Saavedra JE, Keefer LK, Johnson DR, Klaassen CD Waalkes MP: Overexpression of glutathione S-transferase II and multidrug resistance transport proteins is associated with acquired tolerance to inorganic arsenic. Mol Pharmacol 2001, 60:302-309.

35. Yoo SD, Cho Y, Sheen J: Emerging connections in the ethylene signaling network. Trends Plant Sci 2009, 14:270-279.

36. Iqbal NMA, Khan MIR, Asgher M, Fatma M, Khan NA: Cross-talk between sulfur assimilation and ethylene signaling in plants. Plant Signal Behav 2013, 8:1-9.

37. Masood A, lqbal N, Khan NA: Role of ethylene in alleviation of cadmiuminduced photosynthetic capacity inhibition by sulphur in mustard. Plant Cell Environ 2012, 35:524-533.

38. Arteca RN, Arteca JM: Heavy-metal-induced ethylene production in Arabidopsis thaliana. J Plant Physiol 2007, 164:1480-1488.

39. DalCorso G, Farinati S, Maistri S, Furini A: How plants cope with cadmium Staking all on metabolism and gene expression. J Integr Plant Biol 2008, 50:1268-1280

40. Liu Q, Zhou GY, Wen CK: Ethylene signal transduction in Arabidopsis. Zhi Wu Sheng Li Yu Fen Zi Sheng Wu Xue Xue Bao 2004, 30:241-250.

41. Johnson PR, Ecker JR: The ethylene gas signal transduction pathway: a molecular perspective. Annu Rev Genet 1998, 32:227-254.

42. Vierstra RD: The ubiquitin/26S proteasome pathway, the complex last chapter in the life of many plant proteins. Trends Plant Sci 2003, 8:135-142.

43. Mazzucotelli E, Belloni S, Marone D, De Leonardis A, Guerra D, Di Fonzo N, Cattivelli L, Mastrangelo A: The e3 ubiquitin ligase gene family in plants: regulation by degradation. Curr Genomics 2006, 7:509-522.

44. Dowil RT, Lu X, Saracco SA, Vierstra RD, Downes BP: Arabidopsis membrane-anchored ubiquitin-fold (MUB) proteins localize a specific subset of ubiquitin-conjugating (E2) enzymes to the plasma membrane. J Biol Chem 2011, 286:14913-14921.

45. Santos C, Gaspar M, Caeiro A, Branco-Price C, Teixeira A, Ferreira RB: Exposure of Lemna minor to arsenite: expression levels of the components and intermediates of the ubiquitin/proteasome pathway. Plant Cell Physiol 2006, 47:1262-1273.

46. Jobe TO, Sung DY, Akmakjian G, Pham A, Komives EA, Mendoza-Cozatl DG, Schroeder Jl: Feedback inhibition by thiols outranks glutathione depletion: a luciferase-based screen reveals glutathione-deficient gamma-ECS and glutathione synthetase mutants impaired in cadmiuminduced sulfate assimilation. Plant J 2012, 70:783-795.

47. Gou X, He K, Yang H, Yuan T, Lin H, Clouse SD, Li J: Genome-wide cloning and sequence analysis of leucine-rich repeat receptor-like protein kinase genes in Arabidopsis thaliana. BMC Genomics 2010, 11:19.

48. ten Hove CA, Bochdanovits Z, Jansweijer VM, Koning FG, Berke L, SanchezPerez GF, Scheres B, Heidstra R: Probing the roles of LRR RLK genes in Arabidopsis thaliana roots using a custom T-DNA insertion set. Plant Mol Biol 2011, 76:69-83.

49. Ding Y, Chen Z, Zhu C: Microarray-based analysis of cadmium-responsive microRNAs in rice (Oryza sativa). J Exp Bot 2011, 62:3563-3573.

50. Winter D, Vinegar B, Nahal H, Ammar R, Wilson GV, Provart NJ: An "Electronic Fluorescent Pictograph" browser for exploring and analyzing large-scale biological data sets. PLoS One 2007, 2:e718. 
51. Ghose R, Guo T, Vallejo JG, Gandhi A: Differential role of Toll-interleukin 1 receptor domain-containing adaptor protein in Toll-like receptor 2-mediated regulation of gene expression of hepatic cytokines and drug-metabolizing enzymes. Drug Metab Dispos 2011, 39:874-881.

52. Ramel F, Sulmon C, Serra AA, Gouesbet G, Couee I: Xenobiotic sensing and signalling in higher plants. J Exp Bot 2012, 63:3999-4014.

53. de Lorenzo L, Merchan F, Laporte P, Thompson R, Clarke J, Sousa C, Crespi $\mathrm{M}$ : A novel plant leucine-rich repeat receptor kinase regulates the response of Medicago truncatula roots to salt stress. Plant Cell 2009, 21:668-680

54. Du Z, Zhou X, Ling Y, Zhang Z, Su Z: agriGO: a GO analysis toolkit for the agricultural community. Nucleic Acids Res 2010, 38:W64-70

55. Thimm O, Blasing O, Gibon Y, Nagel A, Meyer S, Kruger P, Selbig J, Muller $L A$, Rhee SY, Stitt M: MAPMAN: a user-driven tool to display genomics data sets onto diagrams of metabolic pathways and other biological processes. Plant J 2004, 37:914-939.

doi:10.1186/1471-2229-14-94

Cite this article as: Fu et al:: Transcriptome profiling of genes and pathways associated with arsenic toxicity and tolerance in Arabidopsis. BMC Plant Biology 2014 14:94.

\section{Submit your next manuscript to BioMed Central and take full advantage of:}

- Convenient online submission

- Thorough peer review

- No space constraints or color figure charges

- Immediate publication on acceptance

- Inclusion in PubMed, CAS, Scopus and Google Scholar

- Research which is freely available for redistribution 